\title{
Review on Millimeter Wave Antennas- Potential Candidate for 5G Enabled Applications
}

\author{
Mohammad A Matin ${ }^{1}$ \\ ${ }^{1}$ Department of Electrical and Electronic Engineering, Universiti Teknologi Brunei, Brunei Darussalam \\ *corresponding author, E-mail: matin.mnt@gmail. com
}

\begin{abstract}
The millimeter wave (mmWave) band is considered as the potential candidate for high speed communication services in $5 \mathrm{G}$ networks due to its huge bandwidth. Moreover, mmWave frequencies lead to miniaturization of RF front end including antennas. In this article, we provide an overview of recent research achievements of millimeterwave antenna design along with the design considerations for compact antennas and antennas in package/on chip, mostly in the $60 \mathrm{GHz}$ band is described along with their inherent benefits and challenges. A comparative analysis of various designs is also presented. The antennas with wide bandwidth, high-gain, compact size and low profile with easiness of integration in-package or on-chip with other components are required for $5 \mathrm{G}$ enabled applications.
\end{abstract}

\section{Introduction}

The operation of $5 \mathrm{G}$ enabled applications will be determined based on the spectrum selection, propagation characteristics, antenna technology, transceiver integration, and digital signal processing of wideband technology. The mmWave spectrum is the potential candidate for such wireless technologies due to its huge bandwidth. Therefore, the substantial knowledge about the mmwave spectrum and their characteristics has been collected and a great deal of work has been done toward evolving $5 \mathrm{G}$ wireless systems for commercial applications in the last few years. The attractive features of $60 \mathrm{GHz}$ wireless system make it a choice for such wireless systems. The antenna is the most crucial components of wireless systems as it intensely affects the total receiver sensitivity, thus transceiver designs and choices of digital modulation schemes and the link budget. As a result, the investigation of $60 \mathrm{GHz}$ antenna technology has attracted increasing attention and remarkably, the analysis and design of those antennas is widely reported in numerous research papers [1-8].In [2], a multi-layer antenna is presented with mounted horn integrated on FR4, which can achieve a gain of $11.65 \mathrm{dBi}$. A low-loss/cost substrate integrated waveguide (SIW) feeding scheme to microstrip printed antenna (MPA) is presented in [9] for the first time with the aim of improving the radiation efficiency which was degraded due to conventional planar feeding arrangement in $60-\mathrm{GHz}$ band. In [3], SIW-fed patch array antenna is proposed that can realize a gain $19.6 \mathrm{dBi}$. The Yagi antenna using LTCC technology in [4] has a max gain of $6 \mathrm{dBi}$. The $4 \times 4$ array of Yagi antenna in [5] can achieve a maximum gain of 18 dBi. Nevertheless, these antennas structures are either multi-layered or complex structures, which perhaps fetch difficulties in fabrication. For simplicity of fabrication, Printed log-periodic dipole array (PLPDA) antennas are designed in the mmwave frequency which provides enormous bandwidth with stable gain over the entire frequency range as well as simple geometrical design [10]. A planar fan-like antenna has also demonstrated in [8], which has a peak gain of $7.6 \mathrm{dBi}$ for $60 \mathrm{GHz}$ antenna. Recently, a simple planar antenna with two blade-like antipodal tapered slot patches is reported. The antenna can achieve gain of $10 \mathrm{dBi}$ across $57-64 \mathrm{GHz}$ [11].

It is found from the open literature that there have been many significant developments in the past few years on mmWave antennas. This paper surveys recent advances in research related to mmWave antennas hoping that it will provide valuable information to the reader whose intention is to do research in the area of mmWave antennas for possible integration in future $5 \mathrm{G}$ wireless systems. The paper is structured as follows: section 2 describes the regulations and antenna gain requirement for $60 \mathrm{GHz}$ communication. Section 3 highlights the desirable properties of $60 \mathrm{GHz}$ antennas. Section 4 discusses the recent developments of $60 \mathrm{GHz}$ antenna technology with a performance comparison of various designs. The integration of $60 \mathrm{GHz}$ antenna focuses in section 5. Finally, the author draws a conclusion in section 6 .

\section{2. $60 \mathrm{GHz}$ regulations and Link budget analysis}

The radio-frequency covering the range 30 to $300 \mathrm{GHz}$ is termed as millimeter-wave frequency or extremely highfrequency. The mmWave frequency has appealed a lot of attention due to multi-gigabit communication services including high definition multimedia interface, uncompressed high definition video streaming, high-speed internet, wireless gigabit Ethernet, and close-range automotive radar sensor. However, there have been apprehensions about exploiting mmWave frequency bands owing to higher penetration, precipitation, and foliage losses and the actual amount of these additional propagation losses is varied based on building material, the strength of rain, or the thickness of foliage [12]. The phenomenon of 
larger path loss and oxygen absorption of 10 to $15 \mathrm{~dB}$ per $\mathrm{km}$ near $60 \mathrm{GHz}$ band makes $60-\mathrm{GHz}$ link small which allow frequencies to be reused more often to increase the network capacity. This is an attractive feature in developing system design for future $5 \mathrm{G}$ wireless communication but required high gain antenna. Therefore, antenna arrays with high gain and high-efficiency characteristics are desired in the system design to reduce the cost as well as system performance improvement. Link budget analysis is required to obtain entailed antenna gain for $60 \mathrm{GHz}$ communication. The link budget for largely integrated $60-\mathrm{GHz}$ radios is inadequate. The low transmit power (shown in table 1) and huge path loss at $60 \mathrm{GHz}$ band $(68 \mathrm{~dB} @ 1 \mathrm{~m})$ demands the directional antennas for high data rate, mainly for line-ofsight (LOS) applications. A list of allocated spectrum with maximum transmission power for $60 \mathrm{GHz}$ radio is shown in table 1 .

In case of non-line-of-sight applications, antenna array with high gain and beamforming capabilities is expected for enhancing the link budget and avoiding multipath propagation loss. This usually requires larger arrays, but again high precision fabrication techniques are required as well as error tolerant designs and low loss interconnection. In all cases adequate broadband channel models are required to enable system level design.

Table 1: Spectrum with maximum transmission power for $60 \mathrm{GHz}$ radio

\begin{tabular}{llll}
\hline Countries & Spectrum $(\mathrm{GHz})$ & $\begin{array}{l}\text { Maximum Tx } \\
\text { power }(\mathrm{mW})\end{array}$ & $\begin{array}{l}\text { Maximum antenna } \\
\text { gain }(\mathrm{dBi})\end{array}$ \\
\hline Japan & $59-66$ & $10 \mathrm{~mW}-250 \mathrm{~mW}$ & 47 \\
USA & $57-64$ & 500 & - \\
Canada & $57-64$ & 500 & - \\
Australia & $59.4-62.9$ & 10 & - \\
Europe & $57-66$ & 20 & 37 \\
China & $59-64$ & 10 & 34 \\
Korea & $57-64$ & 10 & - \\
\hline
\end{tabular}

\section{Design considerations for mmWave antennas}

The 5G wireless communication systems need to be designed to support high speed and high data rates with maximum coverage for different applications, such as sensor networks and smart buildings. One of the most essential requirements of such systems is high gain antenna which is desirable as it will balance high path loss at mmWave frequency and decrease the system cost. The other desirable properties for such antenna design are as follows:

- High-efficiency and stable radiation patterns over the entire desired band

- . Compact size and low profile with simplicity of integration with other elements

- Multi-antenna technology

The increase in the gain and efficiency of an antenna are counterpoise by higher propagation loss at high frequencies, so the received signal level needs to be higher. Multiantenna technology increases the receiving signal quality by producing high gain steerable beams to maintain the link. The miniaturization of RF front end and system integration on-package or on-chip without compromising its radiation efficiency, bandwidth and achievable gain are required for high frequency system design. The designed system capacity can be increased by using multiplexing techniques based on baseband signal processing.

Another important design consideration is the feeding structure as the types of feeding arrangement are of great importance in the design of antenna array at mmWave frequencies. Traditional planar feeding arrangements such as microstrip lines and coplanar waveguides experience conduction and radiation losses at mm-wave frequencies, which reduce the overall radiation efficiency and restrict the realizable gain of antenna arrays. The waveguide structure with lower losses is preferred in compare with the microstrip line for the designing of high-gain millimeterwave antenna arrays, but not suitable for large-scale production due to huge fabrication costs and bulky volume. Therefore, Substrate integrated waveguide (SIW) has attracted as alternate choice for millimeter-wave applications which has low-loss characteristics, with planar structure, and low fabrication costs.

\section{4. $60 \mathrm{GHz}$ antenna technology and comparative analysis}

The typical antennas for mmWave communication systems are reflector, lens and horn antennas [13]. These kinds of antennas possess high gain. However, these antennas are not attractive for commercial $60-\mathrm{GHz}$ radios due to high cost, massive size, as a result not possible to integrate on a chip or in a package. Thus, researchers have switched to printed 
antenna arrays for mmWave systems. Printed antennas arrays for example microstrip patch or dipole arrays possess various distinct and attractive features, such as-low profile, small mass, compact and conformable in structure, and ease of fabrication and integration on a chip or in a package. As a result, they are much attractive for commercial $60-\mathrm{GHz}$ radios and hard work is now being commenced for mass market deployment. In [14], a 60-GHz horn-type antenna array is presented which can be made of a multilayered structure by applying multilayer PCB technology. The other designs for $60 \mathrm{GHz}$ antenna technology include patch with Substrate Integrated Waveguide (SIW), multi-layer and multi-patch designs, and different shape with multi slotted patch and so on [15]-[33]. Out of these antennas, different shapes of slotted antenna are normally used to improve the antenna performances due to their geometrical simplicity. In this section, various types of mmWave antennas for $60 \mathrm{GHz}$ band that show huge flexibility and design capability for low-cost, low-profile, low-loss (L3) are illustrated in Table 2 \& 3 for comparison. The selection of the antenna element for constructing the antenna array influences the design and characteristics of millimeter-wave antenna array and the fabrication complexity of the array is directly affected by the geometry of the single element. Table 2 shows the type of antenna used in the open literature and their characteristics such as, impedance bandwidth, gain, fabrication technology and overall dimensions of antenna with linear polarization for the $60 \mathrm{GHz}$ band. Few selected antennas are presented here as reference.

Table 2: Linear polarization for $60 \mathrm{GHz}$ applications

\begin{tabular}{|c|c|c|c|c|c|c|c|}
\hline $\begin{array}{l}\text { Published } \\
\text { literature }\end{array}$ & Type & $\begin{array}{l}\text { No. of } \\
\text { elements }\end{array}$ & BW\% & $\begin{array}{l}\text { Fabrication } \\
\text { technology }\end{array}$ & Substrate type & Gain[dBi] & $\begin{array}{l}\text { Antenna size } \\
\text { dimension } \\
\left(\mathrm{mm}^{3}\right)\end{array}$ \\
\hline Ref.[21] & Grid & 60 & 18.7 & LTCC* & - & 17.7 & $15 \times 15 \times 0.6$ \\
\hline Ref.[22] & $\begin{array}{l}\text { Patch with } \\
\text { embedded cavity }\end{array}$ & 16 & 9.5 & LTCC & - & 18.2 & $18.6 \times 18.6 \times 0.6$ \\
\hline Ref.[23] & $\begin{array}{l}\text { L-probe patch } \\
\text { with soft surface }\end{array}$ & 16 & $29 \%$ & LTCC & - & 17.5 & $14.4 \times 14.4 \times 1$ \\
\hline Ref.[24] & Cavity & 64 & 17.1 & $\begin{array}{l}\text { SIW, } \\
\text { LTCC }\end{array}$ & Ferro A6-M & 22.1 & $24.6 \times 31 \times 2$ \\
\hline Ref.[25] & $\begin{array}{l}\text { Loop-loaded } \\
\text { dipole }\end{array}$ & 14 & 22.1 & $\mathrm{PCB}^{*}$ & Duroid 5880 & 20.1 & $20 \times 20 \times 0.254$ \\
\hline Ref. [3] & $\begin{array}{l}\text { Cavity-backed } \\
\text { Patch }\end{array}$ & 16 & 22.6 & SIW, PCB & Rogers 5880 & 19.6 & $16.3 \times 17.1 \times 2.3$ \\
\hline Ref. [26] & Slot & 256 & 12.1 & PCB & - & 32 & $75 \times 76 \times 6.3$ \\
\hline Ref. [27] & Slot & 144 & 4.1 & SIW, PCB & $\begin{array}{l}\text { Rogers RT/Duroid } \\
6002\end{array}$ & 22 & $30.7 \times 30.7 \times 0.508$ \\
\hline Ref. [28] & $\begin{array}{l}\text { Cavity-backed } \\
\text { wide slot }\end{array}$ & 8 & 11.6 & SIW, PCB & RO3006 & 12.2 & $14 \times 13.5 \times 0.635$ \\
\hline Ref. [39] & Dipole antenna & 16 & 1.63 & LTCC & - & 15.6 & N/A \\
\hline Ref. [40] & Microstrip grid & N/A & 26.83 & LTCC & - & 15 & $15 \times 15 \times 1$ \\
\hline Ref. [24] & Aperture antenna & 64 & 17 & LTCC & - & 22.1 & N/A \\
\hline Ref. [41] & Patch antenna & 16 & 22.6 & LTCC & - & 17 & N/A \\
\hline
\end{tabular}


Table 3: Circular polarization for $60 \mathrm{GHz}$ applications

\begin{tabular}{|c|c|c|c|c|c|c|c|}
\hline $\begin{array}{l}\text { Published } \\
\text { literature }\end{array}$ & Type & $\begin{array}{l}\text { No. of } \\
\text { elements }\end{array}$ & BW\% & $\begin{array}{l}\text { Fabrication } \\
\text { technology }\end{array}$ & $\begin{array}{l}\text { Substrate } \\
\text { type }\end{array}$ & Gain[dBi] & $\begin{array}{l}\text { Antenna size } \\
\text { dimension } \\
\left(\mathrm{mm}^{3}\right)\end{array}$ \\
\hline Ref. [46] & Grid & 4 & 16.4 & & & 14.3 & $15 \times 15 \times 0.9$ \\
\hline Ref. [43] & U-slot patch & 16 & 28.1 & LTCC & - & 16 & $14 \times 16 \times 1.1$ \\
\hline Ref. [45] & Helical antenna & 16 & 22 & LTCC & - & 15.2 & $12 \times 10 \times 2$ \\
\hline Ref. [44] & $\begin{array}{l}\text { Hexagonal } \\
\text { cavity }\end{array}$ & 256 & 5.7 & & & 33.3 & $67.2 \times 67.2$ \\
\hline Ref. [19] & L-probe patch & 16 & 17.8 & CPW, PCB & $\begin{array}{l}\text { Rogers } \\
\text { Duroid } \\
5880\end{array}$ & 14.5 & $14 \times 15.2$ \\
\hline Ref. [42] & $\begin{array}{l}\text { Aperture } \\
\text { coupled patch }\end{array}$ & 4 & 6.7 & SIW, PCB & Rogers & 12.2 & $6.8 \times 6.9$ \\
\hline Ref. [38] & $\begin{array}{l}\text { Slot-coupled } \\
\text { rotated dipole }\end{array}$ & 16 & $\begin{array}{l}14.4 \%(-6 \\
d B)\end{array}$ & SIW, LTCC & $\begin{array}{l}\text { Ferro } \\
\text { A6-M }\end{array}$ & 12.5 & $15.2 \times 15.2$ \\
\hline Ref. [31] & ME dipole & 64 & 18.2 & PCB & $\begin{array}{l}\text { Rogers } \\
5880\end{array}$ & 26.1 & $\begin{array}{l}30.6 \times 34 \times 2.3 \\
61\end{array}$ \\
\hline Ref. [47] & Patch antenna & 16 & 19.67 & LTCC & - & 17.1 & $13 \times 13 \times 0.9$ \\
\hline Ref. [48] & Patch antenna & 16 & 20.44 & LTCC & - & 35 & $13 \times 20 \times 1.4$ \\
\hline
\end{tabular}

Studies on the propagation at $60 \mathrm{GHz}$ demonstrate that the polarization of antenna plays a crucial role in mmWave band. The wave with circular polarization can provide more promising channel performance compared with the linearly polarized wave. Circular polarized high-gain antenna array is a desirable candidate at $60 \mathrm{GHz}$. A list of different designs with circular polarization for $60 \mathrm{GHz}$ spectrum is given (table 3). The applications of circular polarized antenna include secured communication in space mission, high resolution sensor, portable imaging device and microwave energy harvesting.

\section{Technologies for Integrated mmWave antennas}

This section focuses on two solutions in regards to the antenna integration for $60 \mathrm{GHz}$ which are -antennas on chip (AoC) and antenna in package (AiP). The $60-\mathrm{GHz}$ radios to be adopted for $5 \mathrm{G}$ and to cover mass market products and to convene consumer demands, the cost, size and power consumption of antenna-on-chip or antenna-in-package solution must be kept as small as possible. These suggests silicon rather than GaAs as a better choice and the integrated circuit(IC) using silicon technology offers the greatest cost and power savings, especially while considering packaging, integration, and interconnect issues. Due to the latest advancement of integrated circuits (ICs), the complete integration of RF components on a single chip can be achieved except the antenna which often remains offchip. Because, integrated antennas on chip exhibit quit low gain and poor radiation efficiency due to high permittivity and low resistivity of silicon substrate. The performance can be improved using a high resistivity (HR) silicon substrate. Therefore, to get a good-performance low-cost SoC, the antenna and ICs need to be integrated on HR Silicon-on-Insulator (SOI) CMOS.

However, the antenna array designs on Si substrate suffer from large insertion losses into the planar feeding arrangement at mmwave frequencies. Therefore, the crossbreed integration of the antenna on an additional substrate is an innovative technology, which exploits packaging (AiP) and coupling possibilities within such limited space. The desirable trend for front-end miniaturization and system integration on-package or on chip raises the challenge for antenna integration without sacrificing its radiation efficiency, bandwidth and achievable gain. The advantages and disadvantages of AiP and AoC are listed in table 4.

Fabrication process is employed to realize the design and low fabrication cost with good performance mmWave antenna arrays that are attractive and affordable for future $5 \mathrm{G}$ wireless communications. To meet the requirements for compact and high performance $5 \mathrm{G}$ wireless 
systems, Low-Temperature Cofired Ceramic (LTCC) can be used for packaging. LTCC owns the merits of multilayer fabrication capability, stability, and relatively low cost [34], it has become a good choice. On the other hand, Printed circuit board (PCB) technology encounters some problems at very high frequency, that severely distress the system performance and causes reduced efficiency [35]. Compared with PCB technology, LTCC technology is easier to grasp mmWave antenna array structures. The LTCC technology gets preference for most of arrays with multilayered structure and a lot of research papers have been published on compact antenna array for $60 \mathrm{GHz}$ radio applications [3638].

Table 4: Advantages and disadvantages of AiP and AoC

\begin{tabular}{|l|l|l|}
\hline AoC & $\begin{array}{l}\text { Advantages } \\
\text { Integration } \\
\text { simplicity and } \\
\text { compactness }\end{array}$ & $\begin{array}{l}\text { Low gain, low efficiency and } \\
\text { degrade the overall system's } \\
\text { signal to noise ratio (S/N) }\end{array}$ \\
\hline AiP & $\begin{array}{l}\text { High } \\
\text { performance } \\
\text { antenna with } \\
\text { low lows } \\
\text { substrate }\end{array}$ & $\begin{array}{l}\text { Integration and packaging } \\
\text { complexity. Potential } \\
\text { performance degradation due } \\
\text { to hybrid interconnection. }\end{array}$ \\
\hline
\end{tabular}

\subsection{Fabrication processing}

The mmWave antenna designs using low temperature cofired ceramic (LTCC) process are getting increasing attention due to the flexibility in realizing arbitrary number of layers, cross-layer vias, open and embedded cavities [50]. On the other hand, multi-layer PCB technology incurs high mechanical manufacturing cost due to the usage of blind or buried vias. Moreover, PCB technology faces difficulties in the very high frequency band, which brutally affect the system performance and result in reduced efficiency. Therefore, the LTCC technology is the choice of most of arrays with multilayered structures and in general, it can improve antenna performance. Apart from these fabrication technologies, Die-sink electrical discharge machining (EDM) process offers new opportunities for fabrication of cost effective mmWave antennas. Few examples are given in this paper.

\section{a. PCB Process}

The traditional printed circuit board (PCB) process offers low cost design. However, PCB based mmWave antenna design encounters few challenges including fabrication tolerance and reliability of the process. In [20], a center-fed patch antenna array is presented which is derived from the inset dielectric waveguide (IDW) using traditional PCB technology. The presented series-fed patch array antenna can realize comparatively large gain for mmWave applications in compare to the parallel-fed antenna arrays. It also provides a broad bandwidth in compare with the conventional series -fed slot arrays.

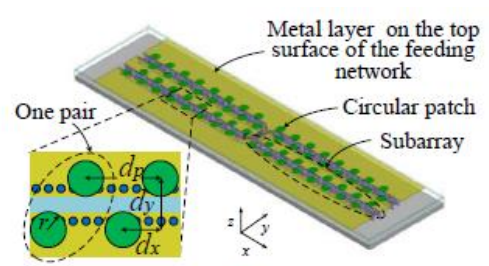

(a)

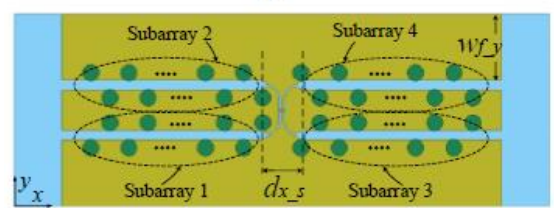

(b)

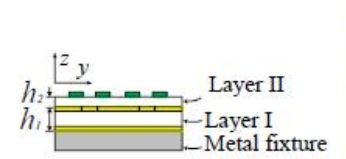

(c)

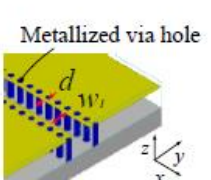

(d)
Figure 1: 3D-view, top view and side view of IDW fed patch antenna array [20]

\section{b. LTCC process}

It is mentioned earlier that LTCC is a multilayer technology which is being exploited for packaging integrated circuits (ICs) and applied to modern wireless communications for single-chip transceiver with comparatively low cost and mass productivity. Figure 2 shows an example of antenna design using LTCC process.
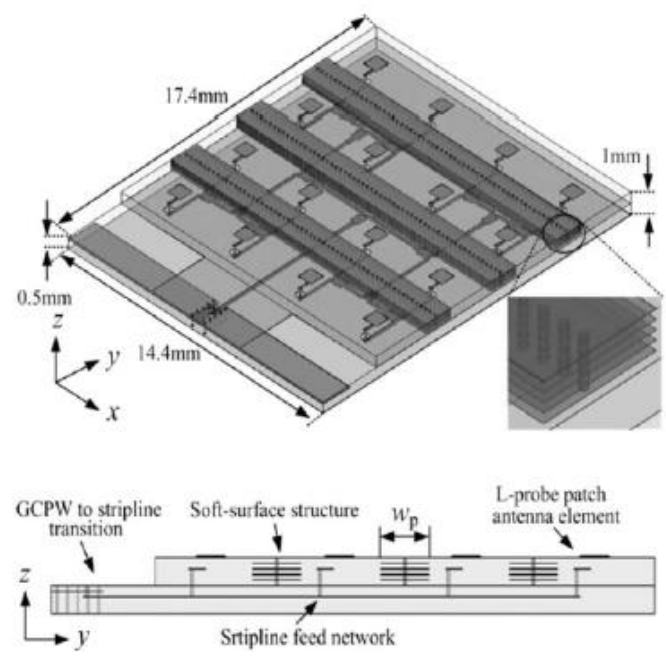

Figure 2: The L-probe patch array antenna [23]

c. Die-sink Electrical Discharge Machining (EDM)

Die-sink electrical discharge machining (EDM) process is a thermoelectric phenomenon which is widely applied in die and mold industries. Recently, this process is used in mmWave antenna design. In [49], a $8 \times 8$-slot planar array is designed from a fully corporate distribution network in ridge gap waveguide technology. This design process introduces new fabrication method called die-sink EDM or die forming which can offer low-cost millimeter wave antennas for $5 \mathrm{G}$ wireless systems. 

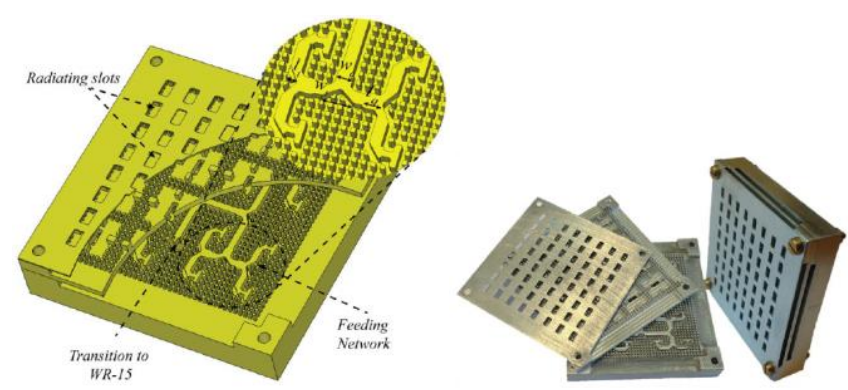

Figure 3: Corporate-fed planar slot antenna array for $60 \mathrm{GHz}$ [49]

\section{Conclusions}

Due to attractive features of mmWave technology, researchers explore this technology for potential applications in 5G wireless systems. The mmWave antennas affect or control the overall performance of such system. The aim of this article is to investigate the recent development made in mmWave antennas. It also highlights the feasibility of antenna in package (AiP) and antenna on chip (AoC) using LTCC and PCB technology.

\section{References}

[1] R. A. Alhalabi, Y.-C. Chiou, and G. M. Rebeiz, -Self shielded high-efficiency Yagi-Uda antennas for $60 \mathrm{GHz}$ communications," IEEE Trans. on Antennas and Propagat., Vol. 59, No. 3, 742-750, 2011.

[2] W. T. Sethi, H. Vettikalladi, B. K. Minhas, and M. A. Alkanhal, High gain and wide-band aperture-coupled microstrip patch antenna with mounted horn integrated on FR4 for $60 \mathrm{GHz}$ communication systems," IEEE Symposium on Wireless Technology and Applications (ISWTA), 359-362, 2013.

[3] Y. Li and K.-M. Luk, -bw-cost high-gain and broadband substrate integrated-waveguide-fed patch antenna array for $60-\mathrm{GHz}$ band," IEEE Trans. on Antennas and Propagat., Vol. 62, No. 11, 2014.

[4] O. Kramer, T. Djerafi, and K. Wu, - Very small footprint $60 \mathrm{GHz}$ stacked Yagi antenna array," IEEE Trans. on Antennas and Propagat., Vol. 59, No. 9, 3204-3210, 2011.

[5] M. Sun, Y. P. Zhang, K. M. Chua, L. L. Wai, D. Liu, and B. P. Gauche, Integration of Yagi antenna in LTCC package for differential 60-GHz radio," IEEE Trans. on Antennas and Propagat., Vol. 56, No. 8, 2008.

[6] A. Dadgarpour, B. Zarghooni, B. S. Virdee, and T. A. Denidni, - Mllimeter-wave high-gain end-fire bow-tie antenna," IEEE Trans. on Antennas and Propagat., Vol. 63, No. 5, 2337-2342, 2015.

[7] P. Cabrol and P. Pietraski, $-60 \mathrm{GHz}$ patch antenna array on low cost liquid crystal polymer (LCP) substrate," IEEE Systems, Applications and Technology Conference (LISAT), 1-6, 2014.
[8] M. Sun, X. Qing, and Z. N. Chen, -60-GHz end-fire Fanlike antennas with wide beamwidth," IEEE Trans. on Antennas and Propagat., Vol. 61, No. 4, 1616-1622, 2013.

[9] W. M. Abdel-Wahab, S. Safavi-Naeini, Wide bandwidth $60 \mathrm{GHz}$ aperture-coupled microstrip patch antennas (MPAs) fed by substrate intergrated waveguide", IEEE Antennas and Wireless Propagation Letters, vol. 10, pp. 1003-1005, 2011.

[10] H.-T. Hsu and T.-J. Huang, -Akoch-shaped logperiodic dipole array (LPDA) antenna for universal ultra-high-frequency (UHF) radio frequency identification (RFID) handheld reader," IEEE Transactions on Antennas and Propagation, vol. 61, no. 9, pp. 4852-4856, 2013.

[11] Ning Wang and PengGao, - A60GHz End-Fire HighGain Tapered Slot Antenna with Side-Lobe Suppression" Progress In Electromagnetics Research Letters, Vol. 55, 2015.

[12]A. I. Sulyman, A. T. Nassar, M. K. Samimi, G. R. Maccartney, T. S. Rappaport, and A. Alsanie, -Raib propagation path loss models for $5 \mathrm{G}$ cellular networks in the $28 \mathrm{GHZ}$ and $38 \mathrm{GHZ}$ millimeter-wave bands," IEEE Commun. Mag., vol. 52, no. 9, pp. 78-86, 2014.

[13] R. B. Dybdal, Millimeter wave antenna technology," IEEE J. Sel. Areas Commun., vol. 1, no. 4, pp. 633-644, Sep. 1983.

[14] A. Enayati, G. A. E. Vandenbosch, and W. D. Raedt, Millimeter-wavehorn-type antenna-in-package solution fabricated in a teflon-basedmultilayer PCB technology," IEEE Trans. Antennas Propag., vol. 61,no. 4, pp. 15811589, Apr. 2013.

[15] Z. Nasimuddin, and N. Chen, Multipatchs multilayered UWB microstrip antennas", IET Microwaves, Antennas \& Propagation, vol. 3, no. 3, pp. 379-386, 2009. [Online]. Available: http://dx.doi.org/ 10.1049/iet-map.2008.0181

[16] W. M. Abdel-Wahab, and S. Safavi-Naeini, Wide bandwidth $60 \mathrm{GHz}$ aperture-coupled microstrip patch antennas (MPAs) fed by substrate integrated waveguide", IEEE Antennas and Wireless Propagation Letters, vol. 10, pp. 1003-1005, 2011. [Online]. Available: http://dx.doi.org/10.1109/LAWP.2011.2168373.

[17] Y. Sung, Bandwidth enhancement of a microstrip linefed printed wide-slot antenna with a parasitic center patch", IEEE Trans. Antennas and Propagation, vol. 60, pp. 1712-1716, 2012.[Online]. Available: http://dx.doi.org/10.1109/TAP.2012.2186224

[18] J. J. Tiang, M. T. Islam, N. Misran, Slot loaded circular microstrip antenna with meandered slits", Journal of Electromagnetic Waves and Applications, vol. 25, no. 13, pp. 1851-1862, 2011. [Online]. Available: http://dx.doi.org/10.1163/156939311797454042

[19] M. J. Li and K. M. Luk, - Low-cost wideband microstrip antenna array for $60-\mathrm{GHz}$ applications," 
IEEE Trans. Antennas Propag., vol. 62, no. 6, pp. 3012-3018, Jun. 2014.

[20] X Bai, S-W Qu, K B Ng, Eenter-fed patch antenna array excited by an inset dielectric waveguide for 60GHz applications, IEEE Trans. Antennas Propag., May 2016.

[21] B. Zhang and Y. P. Zhang, Grid array antennas with subarrays and multiple feeds for $60-\mathrm{GHz}$ radios," IEEE Trans. Angtennas Propag., vol. 60, no. 5, pp. 2270 2275, May 2012.

[22] A. Lamminen, J. Saily, and A. R. Vimpari, $-60 \mathrm{GHz}$ patch antennas and arrays on LTCC with embedded cavity substrates," IEEE Trans. Angtennas Propag., vol. 56, no. 9, pp. 2865-2874, Sep. 2008.

[23] L. Wang, Y. X. Guo, and W. X. Sheng, Wideband high-gain 60-GHz LTCC L-probe patch antenna array with a soft surface," IEEE Trans. Antennas Propag., vol. 61, no. 4, pp. 1802-1809, Apr. 2013.

[24] J. F. Xu, Z. N. Chen, X. M. Qing, and W. Hong, Bandwidth enhancement for a $60 \mathrm{GHz}$ substrate integrated waveguide fed cavity array antenna on LTCC," IEEE Trans. Antennas Propag., vol. 59, no. 3, pp. 826-832, Mar. 2011.

[25] M. J. Li and K. M. Luk, -Alow-profile unidirectional printed antenna for millimeter-wave applications," IEEE Trans. Angtennas Propag., vol. 62, no. 3, pp. 1232-1237, Mar. 2014.

[26] Y. Miura, J. Hirokawa, M. Ando, Y. Shibuya, and G. Yoshida, Đouble-layer full-corporate-feed hollowwaveguide slot array antenna in the $60-\mathrm{GHz}$ band," IEEE Trans. Antennas Propag., vol. 59, no. 8, pp. 2844-2854, Aug. 2011.

[27] X. P. Chen, K. Wu, L. Han, and F.He, -bw-cost high gain planar antenna array for $60-\mathrm{GHz}$ band applications," IEEE Trans. Antennas Propag., vol. 58, no. 6, pp. 2126-2129, June 2010.

[28] K. Gong, Z. N. Chen, X. M. Qing, P. Chen, and W. Hong, Substrate integrated waveguide cavity-backed wide slot antenna for $60-\mathrm{GHz}$ bands," IEEE Trans. Antennas Propag., vol. 60, no. 12, pp.6023-6026, Dec. 2012.

[29] Y Wanlan, M Kaixue, K S. Yeo, and W M Lim, -A compact high-performance patch antenna array for 60GHz applications" IEEE Antennas Wireless Propag. Lett., vol.15, pp. 313-316, Feb. 2016.

[30] M O Sallam, M Serry, S Sedky, and A Shamim, Micromachined On-Chip Dielectric resonator Antenna operating at $60 \mathrm{GHz}$," IEEE Trans. Antennas Propag., vol. 63, no. 8, pp. 3410-3416, Aug. 2015.

[31] Y Li, and K M Luk, - $\mathrm{A} 60-\mathrm{GHz}$ wideband circularly polarized aperture coupled magneto-electric dipole antenna array" IEEE Trans. Antennas Propag., vol. 64, no. 4, pp. 1325-1333, April 2016.

[32] H. Vettikalladi, O. Lafond, and M. Himdi, Highefficient and high gain superstrate antenna for $60-\mathrm{GHz}$ indoor communication," IEEE Antennas Wireless Propag. Lett., vol. 8, pp. 1422-1425, 2009.

[33] A. Lamminen, J. Saily, and A. R. Vimpari, $-60-\mathrm{GHz}$ patch antennas and arrays on LTCC with embeddedcavity substrates," IEEE Trans. Antennas Propag., vol. 56, no. 9, pp. 2865-2874, Sep. 2008.

[34] K. Lim, S. Pinel, M. F. Davis, A. Sutono, C.-H.Lee, D.Heo, A. Obatoynbo, J. Laskar, E.M. Tentzeris, and R. Tummala, RF system- on-package (SOP) for wireless communications," IEEE Microwave Magazine, Vol.3, No.1, pp.88-99, Mar. 2002.

[35] Y. Imanaka, Multilayered Low Temperature Cofired Ceramics (LTCC) Technology". Berlin, Germany: Springer-Verlag, 2005.

[36] J. F. Xu, Z. N. Chen, X. M. Qing, and W. Hong, Bandwidth enhancement for a $60 \mathrm{GHz}$ substrate integrated waveguide fed cavity array antenna on LTCC," IEEE Trans. Antennas Propag., vol. 59, no. 3, pp. 826-832, Mar. 2011.

[37] J. F. Xu, Z. N. Chen, X. M. Qing, and W. Hong, 140GHz TE20- mode dielectric-loaded SIW slot antenna array in LTCC," IEEE Trans. Angtennas Propag., vol. 61, no. 4, pp. 1784-1793, Apr. 2013.

[38] Y. Li, Z. N. Chen, X. M. Qing, Z. J. Zhang, J. F. Xu, and $Z$. H. Feng, - Axal ratio bandwidth enhancement of $60-\mathrm{GHz}$ substrate integrated waveguide-fed circularly polarized LTCC antenna array," IEEE Trans. Angtennas Propag., vol. 60, no. 10, pp. 4619-4626, Oct. 2012.

[39] C. Hui, Y.-X.Guo, and Z. Wang, -60-GHz LTCC wideband vertical off-center dipole antenna and arrays," IEEE Trans. Antennas Propag., vol. 61, no. 1, pp. 153161, Jan. 2013.

[40] Z. Bing, D. Titz, F. Ferrero, C. Luxey, and Z. Zhang, Integration of quadruple linearly-polarized microstrip grid array antennas for $60-\mathrm{GHz}$ antenna-in-package applications," IEEE Trans. Compon., Packag., Manuf. Technol., vol. 3, no. 8, pp. 1293-1300, Aug. 2013.

[41] L. Duixian, J. A. G. Akkermans, H.-C.Chen, and B. Floyd, Packages with integrated $60-\mathrm{GHz}$ aperturecoupled patch antennas," IEEE Trans. Antennas Propag., vol. 59, no. 10, pp. 3607-3616, Oct. 2011.

[42] A. B. Guntupalli and K. Wu, $-60-\mathrm{GHz}$ circularly polarized antenna array made in low-cost fabrication process," IEEE Antennas Wireless Propag. Lett., vol. 13, pp. 864-867, 2014.

[43] H. C. Sun, Y. X. Guo, and Z. L. Wang, $-60-\mathrm{GHz}$ circularly polarized U-slot patch antenna array on LTCC," IEEE Trans. Antennas Propag., vol. 61, no. 1, pp. 430-435, Jan. 2013.

[44] Y. Miura, J. Hirokawa, M. Ando, K. Igarashi, and G. Yoshida, - Acircularly-polarized aperture array antenna with a corporate-feed hollow waveguide circuit in the 60 GHz-band," 2011 IEEE AP-S Int. Sym., Session: 429.2, July 2011.

[45] C. Liu, Y. X. Guo, X. Bao, and S. Q. Xiao, $-60-\mathrm{GHz}$ LTCC integrated circularly polarized helical antenna 
array," IEEE Trans. Antennas Propag., vol. 60, no. 3, pp. 1329-1335, Mar. 2012.

[46] B. Zhang, Y. P. Zhang, D. Titz, F. Ferrero, and C. Luxey, -Acircularly-polarized array antenna using linearly-polarized sub grid arrays for highly-integrated 60-GHz radio," IEEE Trans. Antennas Propag., vol. 61, no. 1, pp. 436-439, Jan. 2013.

[47] W. Zhang, Y. P. Zhang, M Sun, C Luxey, D Titz and F Ferrero, A 60-GHz circularly-polarized array antennain package in LTCC technology," IEEE Trans. Antennas Propag., vol. 61, no. 12, pp. 6228-6232, Dec. 2013.

[48] M. Sun, Y. Q. Zhang, Y. X. Guo, M. F. Karim, O. L. Chuen, M. S. Leong, Integration of circular polarized array and LNA in LTCC as a $60-\mathrm{GHz}$ active receiving antenna," IEEE Trans. Antennas Propag., vol. 59, no. 8, pp. 3083-3089, Aug. 2011.

[49] A. Vosoogh, P. Kildal, "Corporate-Fed Planar $60 \mathrm{GHz}$ Slot Array Made of Three Unconnected Metal Layers Using AMC pin surface for the Gap Waveguide". IEEE Antennas Wireless Propag. Lett., vol.pp, 1-4, no. 99, Dec. 2015.

[50] Z. N. Chen, X. Qing, M. Sun, K. Gong, and W. Hong, "60-GHz antennas on PCB", proc. of 8th European Conference on Antennas and Propagation (EuCAP 2014), pp. 643-646, 6-11 April, 2014. 